\title{
Impact of Limestone Deposit Operation on the Yield of Surrounding Agricultural Land: Case of the Western Rif, Morocco
}

\author{
Ghizlane Fattah ${ }^{1,}$, Fouzia Ghrissi ${ }^{1}$, Jamal Mabrouki ${ }^{2}$ and Hicham Cherifi ${ }^{3}$ \\ ${ }^{1}$ Civil hydraulic and environmental engineering laboratory, Water treatment and reuse structure, Mohammadia School of Engineers, \\ Mohammed V University in Rabat, Avenue Ibn Sina B.P 765, Agdal Rabat, 10090 Morocco \\ ${ }^{2}$ Laboratory of Spectroscopy, Molecular Modeling, Materials, Nanomaterial, Water and Environment, CERNE2D, Mohammed V \\ University in Rabat, Faculty of Science, Avenue Ibn Battouta, BP1014, Agdal, Rabat, Morocco \\ ${ }^{3}$ Sidi Mohamed Ben Abdellah University, Sciences \& Techniques Faculty, Intelligent Systems, Georesources\& Renewable Energies \\ Laboratory (SIGER), B.P. 2202 - Route Imouzzer, Fez Morocco
}

\begin{abstract}
The exploitation of the limestone deposit is carried out in the open air. Its exploitation process has obvious effects on its environment, and in particular on agricultural production in neighboring lands, by suspending fine particles of matter in the air, which can potentially settle in the soil and the water. The latter being essential resources in the agricultural production process. The analysis of the quality of these resources located near the exploited zone as well as in a control zone (reference zone), both located at the level of the mountain of Haouz, of the western Rif, made it possible to assess the 'impact of the exploitation of the limestone deposit on the physico-chemical characteristics of soils and surface water. Soil and water samples were taken in these areas. The results of these analyzes made it possible to assess the level of soil fertility at each identified sampling point, as well as the characterization of surface water intended for irrigation. The results revealed that this exploitation leads to a significant modification of the soil profile of the neighboring agricultural lands, making them less fertile. This exploitation also causes a hardening of the surface layer of the soil, favoring the phenomenon of encrustation of the soil. The only positive point is that surface water is endowed with essential nutrients such as magnesium and phosphorus originating from the dust emitted during the extraction of limestone. An excessive presence of suspended matter could be accompanied by an increase in $\mathrm{pH}$ and thus promote the phenomenon of encrustation of soils when they are irrigated. This reveals that the exploitation of the deposits has generally negative physical and chemical impacts on the soil and consequently on agricultural production.
\end{abstract}

Keywords:agricultural yield, exploitation of the deposit, limestone, dust, soil, water and physicochemical, Western Rif

\section{Introduction}

The exploitation of quarries and the production of aggregates constitute a very important sector for the socio-economic development of the country [1]. Indeed, this sector is located upstream of the activities linked to the realization of a large number of urban development projects. The bodies responsible for carrying out these actions have to extract materials and ores of all kinds to carry out their mission [2]. Indeed, quarrying is the basis of all infrastructures. We need only recall its geological definition to understand this [3]. It is an artificial excavation, generally open to the sky, used to extract building materials (limestone, granite, gypsum, sand [4][5]. Furthermore, it is obvious that quarrying requires the occupation of space. However, this occupation is temporary, since at the end of the exploitation, the said space must be restored. If the exploited sites are not rehabilitated, the quarry holes become groundwater recharge areas due to their shallowness and the permeability of the underlying layers [6][7]. Abandoned quarries can also become uncontrolled dumps or unhealthy housing sites.

The expansion of the mining industry has been aided by the development of technology. This in turn contributes to industrial development, which is an important driver of global growth. The performance of the mining sector is thus considered a prerequisite for a country's development and determines its economic position in the world trade [8]. The production of building materials in the Northern Region is ensured by several quarries extracting alluvial materials to meet the local market demand. The number of these quarries is in constant development with a strong positive relationship to the demand for building materials, which is dependent on the downstream activity of the building and public work sector [9]. Generally, an impact is the change, positive or negative, due to a pressure generated by an activity on the Biophysical environment as well as its consequence on man. Indeed, the impact of a career is very

*Corresponding author:ghizlane_fattah@um5.ac.ma 
variable depending on the type of material to be extracted, the mode of exploitation and the environment of the site; the eco-system. Indeed, it changes the original physical and geochemical characteristics of the soil [10-11-12-13].

\section{Description of the study area}

The present study was carried out in the north of Morocco (Figure 1). The deposit in operation is named theHaouzchainof the Western Rif and belongs to the group of limestone geological formations[5]. Pedological studies of the region highlight two types of soil units namely: ferralitic soils on bar land, overlooking valleys and depressions and hydromorphic soils. The climate is humid Mediterranean type under oceanic influence.Temperatures remain mild in winter, mild in summer both on the coasts and in altitude. They rarely reach $0^{\circ} \mathrm{C}$ in January and the most frequent maxima of this month oscillate between $14^{\circ} \mathrm{C}$ and $18^{\circ} \mathrm{C}$. In summer, the atmosphere warms up noticeably, the most frequent maximum temperatures in July vary between $16^{\circ} \mathrm{C}$ and $26^{\circ} \mathrm{C}$. The average interannual rainfall is $1,800 \mathrm{~mm}$ in the high reliefs.

The study area covers a purely rural area characterized by the presence of towns and villages, generally near the water sources that emerge along the limits of the limestone range. The locomotor activity in the region is subsistence agriculture based mainly on the cultivation of cereals and grazing agriculture.

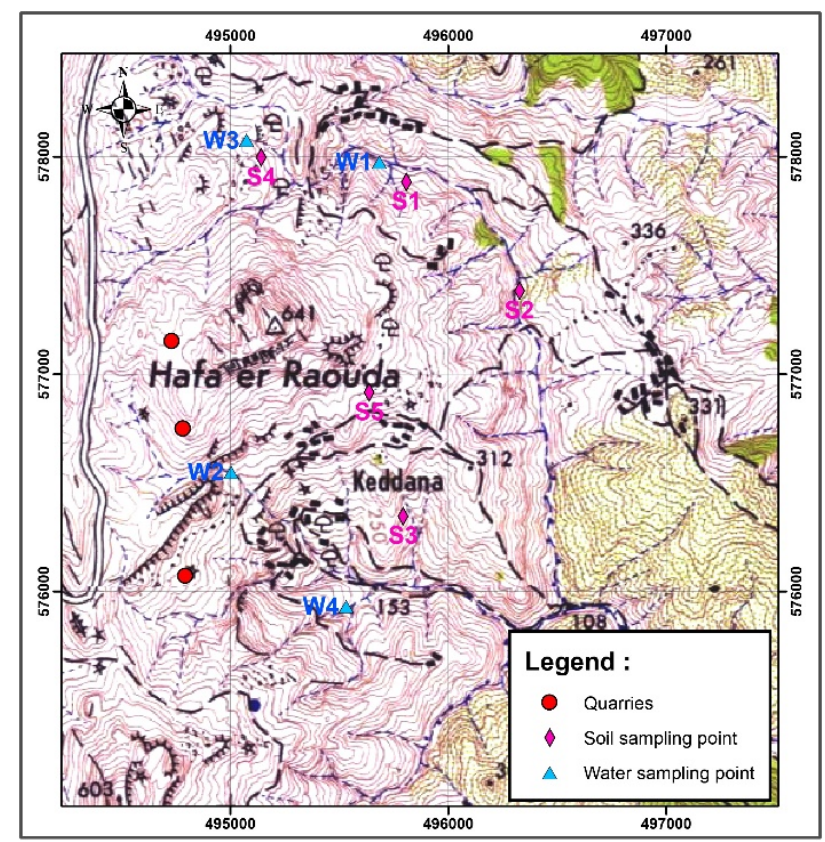

Figure 1 : Site of sample (Tangier topographic map: 1/250000)

\section{Materials and methods}

\subsection{Sampling}

With your hand below the surface of the water, uncork and fill the $500 \mathrm{ml}$ bottle, rinse it and then empty it out of the water. Quickly close the bottle and immerse it in the water to the desired depth. If no precise indication is given, take the sample $30 \mathrm{~cm}$ below the surface of the water [14]. At the truck, remove the METALS bag corresponding to the station to be sampled from the bottle set transport cooler and place it with the boxes of long and short polyethylene gloves in the small field cooler designated for trace metals [15].

The soil sampling sent to the laboratory should usually weigh around 400 grams. However, it must be representative of 20,000 tonnes of soil. It is therefore understandable that the sampling must be done carefully [16]. The choice of sampling area can greatly influence the precision of the soil analysis. It is a relatively simple matter to take a sample from each field if the field is small. On the other hand, very large fields should be divided into smaller sampling areas [17]. It is important, as far as possible, to ensure that each sample area is uniform and separate from those that are obviously different.

Soil fertility can vary according to bedrock composition, soil texture, amount of nutrients removed by the crop or topography. Most differences in fertility, However, can be attributed to previous applications of nutrients, in the form of 
fertilizer or manure [18]. If there is little variability, several soil cores can be pooled into one sample. If the variability is high, it is recommended to take separate samples. If the above field boundaries are known, they can be used to divide larger fields into smaller plots [19]. Samples from plots that clearly differ in composition from the rest of the field should not be pooled into the composite field sample [20]. They should therefore be avoided in ditches, eroded areas, alleys or in the location of old manure or lime piles. If these areas are large enough, it is advisable to take samples from them and have them analysed separately.

\subsection{Physico-chemical analyzes}

\subsubsection{Soil}

Soil analysis is an important part of crop production and nutrition management [21-22].Soil sampling is a three-step process: first, taking a representative sample from each field or plot, then analyzing the sample to determine the amount of available soil nutrients, and finally, using the results to determine optimal fertilizer rates [23].

Total porosity is the volume of pores contained in an apparent volume of a given soil. For a soil sample, the apparent volume is the sum of the solid volume (real volume) and the volume of the gaps. A detailed study of porosity variations under the effect of cultivation practices has not been carried out until now. The present study allows a more in-depth discussion of the consequences of no-tillage systems on soil porosity. Indeed, the main objective of this study is to analyses the changes in porosity of a swelling clay soil under different cropping and tillage systems in the semi-arid zone of Morocco.

\subsubsection{Surface Water}

A number of elements in water can be directly toxic to the crop. Setting toxicity limits for irrigation water is complicated by the reactions that can occur when water reaches the soil. Potentially harmful elements in the water can be inactivated by chemical reactions or accumulate in the soil to levels that are toxic to plants.

Suspended solids, dissolved oxygen, nitrite $\left(\mathrm{NO}^{2-}\right)$, ammonium $\left(\mathrm{NH}^{4+}\right)$ and nitrogen $(\mathrm{N})$, Biochemical Oxygen Demand $\left(\mathrm{BOD}_{5}\right)$ were determined by the methods approved by AFNOR[6]. The Chemical Oxygen Demand (COD) was determined by the dichromate method. The sediments were dried and then weighed to determine the water loss and the fraction below $63 \mu \mathrm{m}$. Organic matter was determined by loss on ignition at $550^{\circ} \mathrm{C}$.

\section{Results and discussion}

\subsection{Impact onSoilquality}

The soil is a powerful medium for water purification and recycling. Clays, hydroxides and organic matter adsorb cations $(\mathrm{Ca}, \mathrm{Mg}, \mathrm{K}, \mathrm{Na}$, heavy metals) and certain organic molecules. Phosphates and nitrogen are well fixed by soil particles; they can however be carried away with these particles (erosion of bare soil) [24]. The microbiological content of the soil can purify the soil of undesirable substances: mineralisation of nitrogen compounds, denitrification, degradation of organic micropollutants (pesticides). Pathogens introduced into the soil are eliminated when the conditions for their survival are unfavourable: UV, competition with native soil microflora [25].

The different elements of soil fertility can undergo degradation processes (OM, nitrogen, ...), leading to a decrease in plant production. In our case the distribution of fertilising elements varies with distance. In cultivated soils, degradation can be caused by excessive tillage and inappropriate soil management practices. Examples include excessive tillage that degrades soil structure and promotes compaction and erosion, too little fertilisation that depletes soil reserves, or salinisation of the soil by irrigation water. The organic matter content of the soil increases when the soil is moved away from the centre, the aggregates are less stable and are more easily dispersed by rain [26]. The decrease in organic matter content and the use of phytosanitary products (pesticides, etc.) and the impact of polluted water lead to a correlative decrease in the biological activity of the soil (figure 2). Earthworms, which are less numerous, no longer carry out the "biological leaching" that ensures the homogenisation and aeration of the soil, while the formation of battance crusts is favoured [27].

In this study, the results indicate an increase in the concentration of conductivity, phosphorus, magnesium, potassium and a decrease in the concentration of organic matter, nitrogen as well as the rate of porosity compared to those of the reference soil. These differences are significant especially for the S5, S4 and S3 stations located near the limestone mining sites and less significant for the S1 and S2 stations(Figure 2).

However, this difference is not significant for the $\mathrm{pH}$ values (Figure 2). 
This means that the exploitation of the limestone deposit in the study area had an impact on the soil parameters by settling of the suspended matter of the exploited rockin the S5, S4 and S3 stations located near the sites from which it enriched the soil with potassium, phosphorus and in magnesium but it demined the fertility of the soil in organic matter and nitrogen as well as the rate of porosity causing the hardening of the surface layer of the soil.

This modification in physicochemical and granulometric parameters of the soil prevents the emergence of young shoots and influences the hydraulic processes on the soil surface and consequently, the agricultural yield of the land surrounding the quarries decreases.

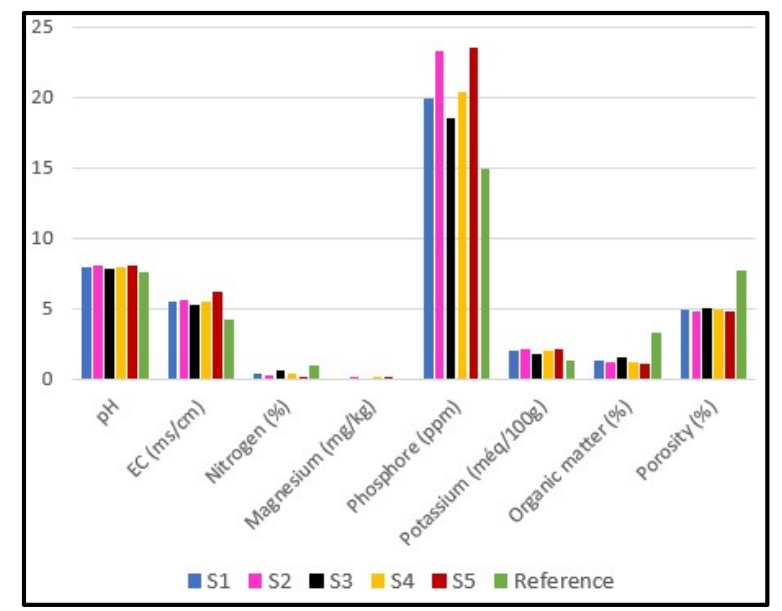

Figure 2 : Characterization of the soil in relation to its distance from the quarries

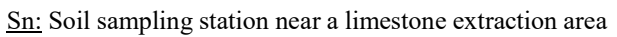
Reference: Soil far from the mining activity

\subsection{Impact on surface water quality}

Soil particles are also carried into surface waters along with agricultural inputs (fertilisers, pesticides) and pollutants from industry, cities and roads. The input of nitrogen and phosphorus causes eutrophication of the river (or coastal zone). The ecological impact of phytosanitary products is recognised but more difficult to assess because of the multiplicity of these substances and their broad spectrum of action.

The $\mathrm{pH}$ of the water conditions the physico-chemical equilibrium, in particular the calco-carbonic equilibrium and therefore the action of the water on the carbonates (attack or deposit). The $\mathrm{pH}$ is basic in surface water. It is alkaline in limestone. Suspended matter can be important in water. It causes discomfort in the appearance of the water and its taste (earthy taste). Turbidity peaks follow heavy rainfall; they are frequent in the Norman Chalk aquifer. Runoff water laden with clay particles - and other undesirable material (W2) - rushes into the sinkholes. The speed of water circulation in the underground network during floods does not allow them to be decanted; moreover, the previously deposited particles are torn out of the cavities and increase the suspended load which ends up at the outlet. Any development that increases surface runoff and soil erosion increases turbidity - agricultural consolidation, drainage of surface water to agricultural soils, filling in of ponds storing pollutants in the soil. Manganese generally accompanies iron in rocks. Like iron, its solubility depends on human activities. It is not very abundant in the waters of the region.

The quality of irrigation water is very important for soil fertility management. Irrigation with sodium-rich water leads to progressive salinisation of the soil. Salinisation increases the osmotic pressure needed by plants to absorb water and nutrients. Irrigation of soils with acidic water results in the leaching of nutrients present as ions $(\mathrm{Ca}, \mathrm{Mg}, \mathrm{K}, \mathrm{P}, \mathrm{S}$, etc.) and can make toxic elements such as aluminium and manganese bioavailable by solubilising them.

Pollution is widespread in space and time; it is chronic and affects large areas. Indeed, current farming and livestock practices strongly influence the water regime and quality.

On the plus side, the surface water is endowed with essential nutrients such as magnesium and phosphorus from the dust emitted during limestone extraction. Excessive suspended solids could lead to an increase in $\mathrm{pH}$ and thus to the scaling of the soil during irrigation. This shows that the exploitation of deposits has generally negative physicochemical impacts on soils and consequently on agricultural production[28].

Figure 3 indicates a slight increase in $\mathrm{pH}$ concentration and conductivity, average oxygen, suspended matter, and interesting phosphorus and magnesium in all sampling stations. The element load becomes more significant in the sites which are close to the quarries. 
However, the modification of the physicochemical parameters of the surface water, neighboring active quarries, intended for irrigation comes from the settling of the dust emitted during the extraction of limestone from the rivers.

This change in parameter thus promotes the phenomenon of incrustation of soils when they are irrigated.

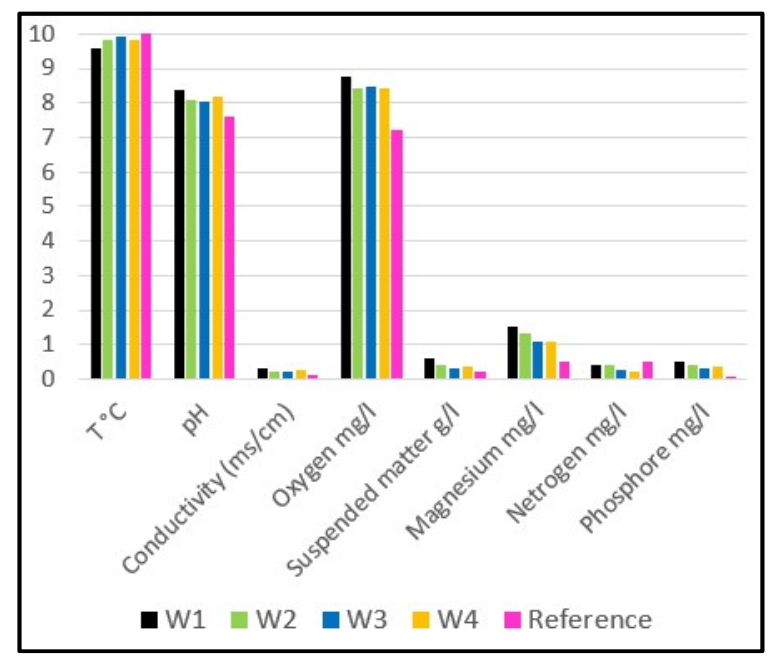

Figure 3 : Characterization of surface water quality in the study area

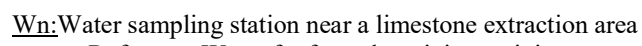
Reference:Water far from the mining activity

\section{Conclusions}

The assessment of the impacts on water and soil shows that this quarry as a whole has more negative than positive impacts on this ecosystem, bearing in mind that, if the accumulative effect of the other quarries is added, the results will surely be increased. The identification of these negative impacts by phase shows that the local actors and promoters are obliged to take, among others, the environmental protection measures that we have mentioned above in order to develop these quarries which present important socio-economic potentialities and participate in the local and regional development and contribute significantly to the financial maintenance of the territorial municipalitywhere this activity is located. This will allow a coherent integration in the local landscape while respecting the receiving ecosystem.

\section{References}

1. Messineo, P. G., \& Barros, M. P. (2015). LithicTechnology, 40(1), 3-20.

2. Zhong, Z., Marcel, T. C., Hartmann, F. E., Ma, X., Plissonneau, C., Zala, M., ... \& Palma Guerrero, J. (2017). New Phytologist, 214(2), 619-631.

3. Li, W., Wu, L., Xie, Z., Tao, L., Zou, K., Li, F., \& Miao, J. (2019). Earth Science Informatics, 12(4), $599-613$.

4. Marvila, M. T., Azevedo, A. R., Barroso, L. S., Barbosa, M. Z., \& de Brito, J. (2020). Construction and Building Materials, 250, 118786.

5. Fattah, G., Ghrissi, F., Mabrouki, J., \&Kabriti, M. (2021). In E3S Web of Conferences (Vol. 234, p. 00018). EDP Sciences.

6. Hamdan, M. H., \& Kamel, M. T. (2011). Flow through variable permeability porous layers. Adv. Theor. Appl. Mech, 4(3), 135-145.

7. Mabrouki, J., El Yadini, A., Bencheikh, I., Azoulay, K., Moufti, A., \& El Hajjaji, S. (2018, July). In International Conference on Advanced Intelligent Systems for Sustainable Development (pp. 22-33). Springer, Cham.

8. Zhang, J., Hoenig, S., Di Benedetto, A., Lancioni, R. A., \&Phatak, A. (2009). Industrial Marketing Management, 38(2), 207-218.

9. Bogus, S. M., Molenaar, K. R., \&Diekmann, J. E. (2006). Construction Management and Economics, 24(8), 829837.

10. Ongley, E. D., Bynoe, M. C., \& Percival, J. B. (1982). In Sediment/Freshwater Interaction (pp. 41-57). Springer, Dordrecht

11. A. Aboubakar, A., El Hajjaji, S., Douaik, A., MfopouMewouo, Y. C., Birang a Madong, R. C., Dahchour, A., ... \&Labjar, N. (2021). International Journal of Environmental Analytical Chemistry, 1-22.

12. Aranda, V., Ayora-Cañada, M. J., Dominguez-Vidal, A., Martin-Garcia, J. M., Calero, J., Delgado, R., ... \& González-Vila, F. J. (2011). Geoderma, 164(1-2), 54-63. 
13. Greenman, D. W., Bennett, G. D., \&Swarzenski, W. V. (1967). US Government Printing Office.

14. Meador, M. R., Cuffney, T. F., \&Gurtz, M. E. (1993). US Geological Survey.

15. Li, Y., \&Migliaccio, K. (Eds.). (2010). CRC Press.

16. Carter, M. R., \&Gregorich, E. G. (Eds.). (2007). CRC press.

17. Pennock, D., Yates, T., \&Braidek, J. (2008). Soil sampling designs. Soil sampling and methods of analysis, [2, 2537.].

18. Desbiez, A., Matthews, R., Tripathi, B., \& Ellis-Jones, J. (2004). Agriculture, ecosystems \& environment, 103(1), 191-206.

19. Dennis, P., Thomas, M. B., \& Sotherton, N. W. (1994). Journal of applied ecology, 361-370.

20. Palm, C. A., Gachengo, C. N., Delve, R. J., Cadisch, G., \&Giller, K. E. (2001). Agriculture, ecosystems \& environment, 83(1-2), 27-42.

21. Smith, K. A., \& Mullins, C. E. (1991). SMR, 873, 7.

22. Peverill, K. I., Sparrow, L. A., \& Reuter, D. J. (Eds.). (1999). CSIRO publishing.].

23. Pueyo, M., Mateu, J., Rigol, A., Vidal, M., López-Sánchez, J. F., \& Rauret, G. (2008). Environmental pollution, $152(2), 330-341$.

24. Martínez-Zavala, L., \&Jordán, A. (2008). Soil Use and Management, 24(1), 108-117.

25. Byappanahalli, M., \& Fujioka, R. (2004). Water Science and Technology, 50(1), 27-32

26. Burke, I. C., Yonker, C. M., Parton, W. J., Cole, C. V., Flach, K., \& Schimel, D. S. (1989). Soil science society of America journal, 53(3), 800-805.

27. Cheng, W. C., \&Kuo, M. T. (2010). Groundwater Monitoring \& Remediation, 30(4), 73-80.

28. Dekker, L. W., \&Ritsema, C. J. (1996). Catena, 28(1-2), 89-105.

29. Campbell, G. S., Jungbauer Jr, J. D., Bristow, K. L., \& Hungerford, R. D. (1995). Soil Science, 159(6), 363-374. 